\title{
Evaluation of calving indicators measured by automated monitoring devices to predict the onset of calving in Holstein dairy cows
}

\author{
V. Ouellet, ${ }^{*}$ E. Vasseur, $†$ W. Heuwieser,‡ O. Burfeind, $¥ X$. Maldague, $\S$ and É. Charbonneau*1 \\ *Département de sciences animales, Université Laval, Québec, G1V 0A6, Canada \\ †Organic Dairy Research Center, University of Guelph, Campus d'Alfred, Ontario, K0B 1A0, Canada \\ ¥Clinic for Animal Reproduction, Faculty of Veterinary Medicine, Freie Universität Berlin, Koenigsweg 65, 14163 Berlin, Germany \\ §Département de génie électrique et de génie informatique, Université Laval, Québec, G1V 0A6, Canada
}

\begin{abstract}
Dystocias are common in dairy cows and often adversely affect production, reproduction, animal welfare, labor, and economics within the dairy industry. An automated device that accurately predicts the onset of calving could potentially minimize the effect of dystocias by enabling producers to intervene early. Although many well-documented indicators can detect the imminence of calving, research is limited on their effectiveness to predict calving when measured by automated devices. The objective of this experiment was to determine if a decrease in vaginal temperature (VT), rumination (RT), and lying time (LT), or an increase in lying bouts (LB), as measured by 3 automated devices, could accurately predict the onset of calving within 24, 12 , and $6 \mathrm{~h}$. The combination of these 4 calving indicators was also evaluated. Forty-two multiparous Holstein cows housed in tie-stalls were fitted with a temperature logger inserted in the vaginal cavity $7 \pm 2 \mathrm{~d}$ before their expected calving date; VT was recorded at 1-min intervals. An ear-attached sensor recorded rumination time every hour based on ear movement while an accelerometer fitted to the right hind leg recorded cow position at 1-min intervals. On average, VT were 0.3 $\pm 0.03^{\circ} \mathrm{C}$ lower, and RT and LT were $41 \pm 17$ and $52 \pm 28$ min lower, respectively, on the calving day compared with the previous $4 \mathrm{~d}$. Cows had $2 \pm 1$ more LB on the calving day. Of the 4 indicators, a decrease in $\mathrm{VT} \geq 0.1^{\circ} \mathrm{C}$ was best able to predict calving within the next $24 \mathrm{~h}$ with a sensitivity of $74 \%$, specificity of $74 \%$, positive and negative predictive values of 51 and $89 \%$, and area under the curve of 0.80 . Combining the indicators enhanced the performance to predict calving within the next 24, 12, and $6 \mathrm{~h}$ with best overall results obtained by combining the 3 devices for prediction within the next $24 \mathrm{~h}$ (sensitivity: $77 \%$, specificity:
\end{abstract}

Received July 3, 2015.

Accepted October 14, 2015.

${ }^{1}$ Corresponding author: edith.charbonneau@fsaa.ulaval.ca
$77 \%$, positive and negative predictive values: 56 and $90 \%$, area under the curve: 0.82 ). These results indicate that a device that could simultaneously measure these 4 calving indicators could not precisely determine the onset of calving, but the information collected would assist dairy farmers in monitoring the onset of calving. Key words: dairy cow, calving indicator, onset of calving, test performance

\section{INTRODUCTION}

Calving is a critical time for both the dam and the calf (Schuenemann, 2012). Difficult births, known as dystocias, are common in dairy cows (Lombard et al., 2007). Studies show that dystocia rates in the United States range from 28.6 to $51.2 \%$ in primiparous cows and from 10.7 to $29.4 \%$ in multiparous cows (Meyer et al., 2001; Lombard et al., 2007). Dystocias are associated with increased risk of stillbirth, calf mortality before $30 \mathrm{~d}$ of age, and morbidity (Lombard et al., 2007). They also increase the likelihood of trauma on the dam (Schuenemann et al., 2011), retained placenta (Oltenacu et al., 1988), uterine disorders (Sheldon et al., 2009), and decreased milk yield (Dematawewa and Berger, 1997; Rajala and Gröhn, 1998). Furthermore, dystocia is negatively associated with fertility and dam survival (Tenhagen et al., 2007). Prevention of dystocia in dairy cows should, therefore, be a high priority in farm management.

Predicting the onset of parturition can help preserve the integrity of the newborn calf and protect the dam during difficult birth situations by facilitating timely human intervention (Shah et al., 2006; Palombi et al., 2013). Moreover, predicting calving time allows careful management around the time of parturition, thus minimizing unnecessary pain and distress especially in situations requiring humane intervention (Miedema et al., 2011b). External signs such as pelvic ligament relaxation, udder distension, teat filling, vaginal discharge, vulva edema, and behavior changes are often used to predict the onset of calving in dairy cows either 
manually, visually, or by video observation (Berglund et al., 1987; Streyl et al., 2011). Such assessments are subjective and time consuming, and the signs themselves vary widely among dairy cows. Furthermore, whereas the number of farms is decreasing in North America and Europe, the number of cows per farm is increasing. Hence, less time is accorded to individual cow supervision around parturition time, especially in small operation farms. Therefore, an automated device that could accurately predict the onset of calving would be valuable to minimize the effects of dystocia on dairy cows.

Changes in cow behavior and physiology observed on the day of calving have been well documented. Schirmann et al. (2013) report that cows spent, on average, $63 \pm 30 \mathrm{~min}$ less time ruminating on the day of calving. Miedema et al. (2011a) and Jensen (2012) report an increase of lying bouts (LB) on the day of calving compared with a control period during gestation, whereas a decrease of $1 \mathrm{~h}$ in daily duration of lying time (LT) was observed. A decrease in body temperature before the onset of parturition has also been reported for dairy cows (Burfeind et al., 2011; Streyl et al., 2011). Burfeind et al. (2011) report that a decrease in vaginal temperature (VT) of $\geq 0.3^{\circ} \mathrm{C}$ over $24 \mathrm{~h}$ as measured by a temperature logger can predict calving within $24 \mathrm{~h}$ with a sensitivity (Se) ranging from 62 to $71 \%$ and with a specificity (Sp) ranging from 81 to 87\%. Rumination time (RT), VT, LB, and LT show measurable changes that are consistent between individuals. Therefore, RT, VT, LB, and LT are considered to be useful calving indicators that can help predict the onset of parturition.

Various automated devices that record RT and the number of LB and LT are available commercially for producers. To our knowledge, the test performance of those calving indicators measured by automated monitoring devices has not been determined. Therefore, the objective of this study was to determine the performance of 3 automated devices to predict the onset of calving based on measuring 4 calving indicators (decrease of VT, RT, and LT; increase of LB). Specifically, we set out (1) to investigate the test performance of the calving indicators during 3 time periods (within the next 24, 12, and $6 \mathrm{~h}$ ) before calving, and (2) to evaluate the test performance using combined calving indicators. We hypothesized that, of the 4 calving indicators, a decrease in VT, recorded by a temperature logger, would obtain the highest test performance to predict calving, with the best predictive value for a calving prediction within the next $24 \mathrm{~h}$, and that combining the indicators would improve the predictive performance of the individual indicators.

\section{MATERIALS AND METHODS}

The study was conducted on a commercial dairy farm (Saint-Anselme, QC, Canada), which had a milking herd of 108 Holstein cows producing, on average, $10,390 \mathrm{~kg} / \mathrm{cow}$ per yr. All experimental procedures were approved by the Animal Care Committee from Université Laval, Quebec, Canada.

\section{Animals, Housing, and Feeding}

A total of 42 multiparous Holstein cows (average \pm SD; parity: $1.9 \pm 1.2$; gestation length: $281 \pm 3 \mathrm{~d}$; calving interval: $408 \pm 52 \mathrm{~d}$ ) housed in freestalls were enrolled from November 2013 to June 2014. About 21 d before their expected calving date, the cows were moved to 1 of the 12 tie-stalls reserved for calving (mean dimension $2.4 \mathrm{~m}$ long $\times 1.3 \mathrm{~m}$ wide; chain length 0.60 to $0.63 \mathrm{~m}$ ). All 12 tie-stalls were fitted with a water bed mattress (DCC waterbeds HQ, Reedsburg, WI) covered with a thin layer of sawdust. A TMR was provided once daily (at $0800 \mathrm{~h}$ ) consisting of $54 \%$ corn silage, $21 \%$ alfalfa hay, and $26 \%$ concentrate and minerals on a DM basis. Feed was pushed up 4 times per day. Water was freely available from water bowls (1 per 2 neighboring cows).

\section{Experimental Measurements}

Cows were fitted with 3 automated devices to measure 4 calving indicators (i.e., VT, RT, LB, and LT). Vaginal temperature was recorded continuously every minute using a microprocessor-controlled temperature data logger (Minilog II-t, Vemco Ltd., Halifax, Canada) as validated by Vickers et al. (2010). The temperature data loggers were attached to a modified, controlled, internal drug-release device without progesterone (CIDR, InterAg, Hamilton, New Zealand) and inserted into the vaginal cavity $6 \pm 2 \mathrm{~d}$ before the predicted calving date, as described by Burfeind et al. (2011). During the process of calving, the temperature logger was expelled from the vaginal cavity and collected by the farm staff, resulting in a sudden decrease in measured temperature, as described by Burfeind et al. (2011). The time of complete expulsion of the logger was established as the calving time for each cow. The temperature data were downloaded after calving.

Rumination time was measured continuously every hour using a 3-dimensional accelerometer (SensOor; Agis Automatisering BV, Harmelen, the Netherlands) designed to be attached to the ear identification tag of the cows as validated by Bikker et al. (2014). Rumination data were sent through a wireless connection, via routers and coordinators, to an on-farm computer 
and was available through a web-based application, as described by Bikker et al. (2014). The cows were equipped with the ear-attached sensor $7 \pm 1 \mathrm{~d}$ before their predicted calving date. Measurements were taken starting at $6 \mathrm{~d}$ before the anticipated calving date until calving. Rumination data were downloaded from the CowManager SensoOr system every day until the time of calving.

The position of the cow (lying or standing) was recorded continuously every minute using an Onset Pendant $\mathrm{G}$ data logger (Onset Computer Corporation, Bourne, MA) as validated for measuring the lying behavior of dairy cows by O'Driscoll et al. (2008). Cows were fitted with the device $6 \pm 2 \mathrm{~d}$ before their expected calving date. The data loggers were wrapped in VetWrap cohesive bandage (3M Products, St. Paul, $\mathrm{MN}$ ) to provide cushioning and were placed on the right hind leg of the cow. The data were downloaded after calving using Onset HOBOware Software (Onset Computer Corporation) and exported to Microsoft Excel (Microsoft Corp., Redmond, WA). Lying time and the number of LB were computed using Excel macros with LB defined as a period of lying for at least 2 consecutive min (Jensen, 2012) separated by periods of walking or standing (Miedema et al., 2011a).

The ambient temperature $\left(\mathbf{A T},{ }^{\circ} \mathrm{C}\right)$ and the relative humidity (RH, \%) of the barn were measured continuously every minute throughout the research project using a temperature and $\mathrm{RH}$ data logger (HOBO U23 Pro v2, Onset Computer Corporation) secured on the barn's ceiling about $1 \mathrm{~m}$ above the cows. The temperaturehumidity index (THI) was calculated using the equation reported by Kendall et al. (2008): THI $=(1.8 \times$ $\mathrm{AT}+32)-[(0.55-0.0055 \times \mathrm{RH}) \times(1.8 \times \mathrm{AT}-26)]$.

\section{Statistical Analysis}

Data were analyzed with SAS 9.3 (2011, SAS Institute Inc., Cary, NC). During the study, VT, LB, and LT were measured every minute by their respective automated device. For further analysis, hourly means were calculated for each cow independently. Vaginal temperatures below $38.0^{\circ} \mathrm{C}$ were considered to be artifacts due to movement of the temperature logger and were excluded from the data set as described by Burfeind et al. (2011). Rumination time was already calculated per hour by the CowManager SensoOr system and expressed as a percentage of behavior per hour for each cow. The percentage was then transformed (i.e., divided by 100 and multiplied by 60) to have the RT in minutes per hour. Each calving indicator was summarized per day to obtain 1 value per cow per day and in 6 -h periods to obtain 4 values per cow per day. The number of LB was square-root transformed to meet the assumption of variance homogeneity. Pearson correlations between THI and VT, RT, LB, and LT were calculated using PROC CORR of SAS.

Differences in RT, LB, and LT between the day of calving assigned $\mathrm{d} 0$ and the $4 \mathrm{~d}$ antepartum assigned $\mathrm{d}-4,-3,-2$, and -1 were determined using PROC GLIMMIX of SAS with the cow as a random effect. For VT, PROC MIXED was used with a model that assumed heterogeneity of variance to account for the normal modification in the amplitude of temperature for the baseline compared with the day of calving. To explore the approximate time of change for all indicators, differences between the last twenty 6 - $\mathrm{h}$ periods before calving were also calculated using PROC GLIMMIX of SAS with cows as random effect and time of day (morning, afternoon, evening, and night) set as a covariate with 4 levels. Morning was defined as the period from 0600 to $1200 \mathrm{~h}$, afternoon from 1200 to 1800 $\mathrm{h}$, evening from 1800 to $0000 \mathrm{~h}$, and night from 0000 to $0600 \mathrm{~h}$.

Differences between each indicator for a particular 6 -h period, and the equivalent 6 -h period $24 \mathrm{~h}$ previously, were calculated for the last $120 \mathrm{~h}$ before calving. Receiving operating characteristic (ROC) analyses for the differences were then conducted using PROC LOGISTIC of SAS to determine the diagnostic performance and cut-off points of a decrease in VT, RT, and LT, and an increase in LB. Cut-off points were defined as the threshold calculated for each indicator optimizing both Se and Sp for predicting calving. The continuous variable was the difference in VT, RT, $\mathrm{LB}$, or $\mathrm{LT}$, whereas the classification variable was the occurrence of calving within 24, 12, or $6 \mathrm{~h}$. Because indicators were summarized in 6 -h periods, 4,2 , and 1 positive events, defined as the occurrence of calving within the 24, 12, or $6 \mathrm{~h}$, existed per cow, respectively. A prediction of calving was considered when a decrease in VT, RT, LT, or an increase in LB, were observed and were greater or equal to the cut-off point.

Test characteristics (Se, Sp, and predictive values) for predicting the onset of calving for each cut-off point and the $95 \%$ confidence interval were then calculated using PROC FREQ of SAS. Sensitivity was defined as the proportion of positive events (occurrence of calving within 24,12 , or $6 \mathrm{~h}$ ) correctly predicted by the test (calving correctly predicted/total calving events). Specificity was defined as the proportion of negative events (absence of calving within 24, 12, or $6 \mathrm{~h}$ ) correctly diagnosed as being negative by the test (absence of calving correctly predicted/total of absence of calving). The positive predictive value was defined as the proportion of events with a positive prediction of calving that resulted in a calving within the expected time interval (calving correctly predicted/total of calving 
predicted). The negative predictive value was defined as the proportion of events with a negative prediction for calving that were correctly diagnosed negative by the test (absence of calving correctly predicted/total of absence of calving predicted).

After individual evaluation of each calving indicator, it was possible to measure the test characteristics of combinations because the indicators were not correlated. This analysis was done using a multivariate logistic regression in SAS, and was followed by PROC LOGISTIC and PROC FREQ to compute the area under the curve and to evaluate performance of each combination. Observations for a specific time preceding calving with missing data from 1 of the indicators were excluded from this analysis.

\section{RESULTS AND DISCUSSION}

During the study, average daily ambient temperature $( \pm \mathrm{SD})$ was $13.6 \pm 2.6^{\circ} \mathrm{C}$, whereas THI was $56.7 \pm 3.9$. Vaginal temperature and THI $(\mathrm{r}=0.06 ; P<0.01)$, RT and THI $(\mathrm{r}=0.06 ; P<0.01)$, and LT and THI $(\mathrm{r}=$ $0.10 ; P<0.01)$ were correlated. The number of LB and THI were not correlated $(P>0.05)$. Considering the low or lack of correlation observed between THI and all the indicators, this measure was not used for further analysis. No significant correlation was observed between the 4 indicators $(P>0.05)$.

Ten cows were excluded from the analysis due to technical problems with 1 of the 3 automated devices (e.g., 8 cows lost their temperature logger before calving, and 2 cows did not have RT data due to technical problems with the rumination sensor). Therefore, 32 multiparous cows were included in the final analysis with data collected from the 3 devices. In the experiment, 39,691 of the 230,400 VT measures (17\%) were below $38^{\circ} \mathrm{C}$ and excluded from further analysis. A total of $66 \mathrm{~h}$ were excluded from the RT analysis $(0.02 \%)$ due to loss of signal from the system. Calvings were distributed irregularly throughout the day with 5 calv- ings occurring in the morning, 8 in the afternoon, 9 in the evening, and 10 in the night. Only 2 cows calved on their predicted date, whereas 14 cows calved before (average $\pm \mathrm{SD}$; days before the predicted calving date: $3.0 \pm 1.5 \mathrm{~d}$ ) and 16 cows calved after (average \pm SD; days after the predicted calving date: $3.1 \pm 1.7 \mathrm{~d}$ ) their predicted date.

\section{Differences Between Days}

Cows exhibited distinctive changes in the 4 calving indicators within the last $24 \mathrm{~h}$ before parturition compared with the $4 \mathrm{~d}$ precalving (Table 1 ). Mean VT was lower $(P<0.05)$ on the day of calving compared with $1,2,3$, and $4 \mathrm{~d}$ before calving. Vaginal temperature recorded on the $4 \mathrm{~d}$ before the day of calving did not significantly differ. An average decrease (mean \pm $\mathrm{SE})$ of $0.3 \pm 0.03^{\circ} \mathrm{C}(P<0.05)$ was observed on the day of calving compared with $4 \mathrm{~d}$ before parturition. This agrees with the findings of Burfeind et al. (2011) and Streyl et al. (2011) who also measured a decrease of $0.3^{\circ} \mathrm{C}$ in $\mathrm{VT}$ the day of calving compared with the preceding days. The similarity between the findings confirms that the amplitude of VT variations before calving is relatively constant in Holstein dairy cows.

Similarly, RT was lower $(P<0.05)$ on the calving day compared with the $4 \mathrm{~d}$ precalving (Table 1 ). No significant difference was observed between the $4 \mathrm{~d}$ before parturition. Cows spent, on average (mean $\pm \mathrm{SE}$ ), $41 \pm 17 \mathrm{~min} / 24 \mathrm{~h}(P<0.05)$ less time ruminating on the calving day compared with the $4 \mathrm{~d}$ before calving, which is comparable but lower than the decrease of $63 \pm$ $30 \mathrm{~min} / 24 \mathrm{~h}$ observed by Schirmann et al. (2013). The discrepancy in the results could partly be related to the different devices used to measure the RT. Schirmann et al. (2013) used a rumination collar based on an acoustic measure, whereas a rumination sensor based on ear movements was used in our study. Moreover, the cows in Schirmann et al. (2013) were checked multiple times for relaxation of tail ligament, vulval discharge,

Table 1. Daily vaginal temperature (mean $\pm \mathrm{SE}$ ), daily rumination time (mean $\pm \mathrm{SE}$ ), daily number of lying bouts (mean $\pm \mathrm{SE}$ ), and daily lying time (mean $\pm \mathrm{SE}$ ) on the $4 \mathrm{~d}$ before and the day of parturition for dairy cows $(\mathrm{n}=32$ multiparous cows)

Days relative to calving

\begin{tabular}{|c|c|c|c|c|c|c|}
\hline Indicator $^{1}$ & -4 & -3 & -2 & -1 & 0 & $P$ \\
\hline
\end{tabular}

\footnotetext{
${ }^{\mathrm{a}-\mathrm{c}}$ Means within a row with different superscripts differ $(P<0.05)$.

${ }^{1}$ Indicators: $\mathrm{VT}=$ vaginal temperature; $\mathrm{RT}=$ rumination time; $\mathrm{LB}=$ lying bouts; $\mathrm{LT}=$ lying time.

${ }^{2}$ Values were square root transformed to meet variance homogeneity assumption. Back-transformed values are shown in the table.
} 
and milk letdown. They were moved to a calving pen when calving was considered imminent, which was, on average, less than $4 \mathrm{~h}$ before the expulsion of the calf. Moving the cows at that time could have contributed to the decrease in RT, resulting in the greater overall decrease observed in their trial. In our study, fewer changes in the environment occurred because cows were moved to a tie-stall reserved for calving $21 \mathrm{~d}$ before their expected calving, where they later calved.

The daily number of LB was also influenced by calving time, which corroborates earlier findings (Huzzey and Von Keyserlingk, 2005; Miedema et al., 2011a; Jensen, 2012). On a daily basis, our results indicate that the number of LB started to increase from $\mathrm{d}-3$ before parturition (Table 1). A maximum of LB per day was reached on the calving day. On average (mean $\pm \mathrm{SE}), 2 \pm 1$ more $\mathrm{LB}(P<0.05)$ were found on the day of calving compared with the $4 \mathrm{~d}$ precalving. Our result is lower than that measured in 2 other studies that observed 7.8 and 7 more LB during the last $24 \mathrm{~h}$ before parturition compared with $24 \mathrm{~h}$ and $4 \mathrm{~d}$ precalving, respectively (Miedema et al., 2011a; Jensen, 2012). The cause of variation in the increase of LB observed on the calving day between the studies might be due to the different housing systems. Miedema et al. (2011a) group-housed their cows in a large straw-bedded barn, and Jensen (2012) kept their cows in individual calving pens, also bedded with deep straw; the cows in our study were kept in a tie-stall with a thin layer of sawdust. Cows in a tie-stall are more restrained in their movements, which could explain the smaller increase in LB observed on the day of calving compared with the days before. Furthermore, the differences observed between the studies can be partly explained by the definitions of the calving time. Miedema et al. (2011a) and Jensen (2012) defined calving time as when the calf was fully expelled, whereas our calving time was set to when the temperature logger was fully expelled.

Daily LT was, on average, lower $(P<0.05)$ on the day of calving compared with $\mathrm{d}-4$ before calving (Table 1). Variation for this indicator was progressive and reached a nadir on the day of calving. The amplitude of variation in daily $\mathrm{LT}$ (mean $\pm \mathrm{SE} ; 52 \pm 28 \mathrm{~min}$ ) between the day of calving compared with the $4 \mathrm{~d}$ before parturition was similar to previous studies. Miedema et al. (2011a) and Jensen (2012) also measured a decrease in LT of about an hour on calving day compared with the control period.

\section{Difference Between 6-h Periods}

Vaginal temperatures were lower $(P<0.05)$ during the last three 6 -h periods (18 to $0 \mathrm{~h}$ ) compared with the periods from 120 to $24 \mathrm{~h}$ before calving and tended to be lower than VT measured during 24 to $18 \mathrm{~h}$ before calving (Figure 1A). Burfeind et al. (2011), in 3 experiments, also observed that VT reached a minimum of respectively 18,13 , and $15 \mathrm{~h}$ before the onset of calving. The time of day (morning, afternoon, evening, and night) had an effect $(P<0.001)$ on VT during the last $120 \mathrm{~h}$ before calving (Figure 2A). Burfeind et al. (2011) observed that VT exhibited a diurnal rhythm throughout the experiment with a minimum reached in the night (0000 to $0600 \mathrm{~h}$ ) and a maximum reached during the evening (1800 to $0000 \mathrm{~h}$ ).

Rumination time reached a minimum in the last 6 - $\mathrm{h}$ period before parturition (Figure 1B). In the last $24 \mathrm{~h}$ before calving, the RT declined in the last 6 -h period before calving compared with the 12 to $6 \mathrm{~h}$ before calving and was lower $(P<0.05)$ than the periods 24 to $12 \mathrm{~h}$ before the onset of parturition. Cows spent, on average (mean $\pm \mathrm{SE}$ ), $162.8 \pm 8.0 \mathrm{~min} / 6 \mathrm{~h}$ ruminating during the periods from 120 to $6 \mathrm{~h}$ before calving and $131.6 \pm 7.5 \mathrm{~min} / 6 \mathrm{~h}$ in the last $6 \mathrm{~h}$ before calving. This result agrees with previous studies where RT was significantly reduced by $25.6 \mathrm{~min} / 6 \mathrm{~h}$ in the final $6 \mathrm{~h}$ before calving and by $10 \mathrm{~min} / 2 \mathrm{~h}$ in the last $4 \mathrm{~h}$ antepartum (Büchel and Sundrum, 2014; Pahl et al., 2014). The time of day (morning, afternoon, evening, night) had a significant effect $(P<0.01)$ on RT with cows ruminating less during the morning and afternoon, and more in the evening and at night (Figure 2B).

The number of $\mathrm{LB}$ reached a maximum in the last 6 $\mathrm{h}$ before parturition (Figure 1C). In the last $24 \mathrm{~h}$, the number of LB was higher $(P<0.05)$ during the period 6 to $0 \mathrm{~h}$ before calving than the period 24 to $18 \mathrm{~h}$. The increased number of LB observed in the last $6 \mathrm{~h}$ before the onset of parturition is well documented (Miedema et al., 2011a; Jensen, 2012) and reflects the increased degree of restlessness and the growing discomfort of the cow with the imminence of calving. The time of day (morning, afternoon, evening, night) had no effect ( $P$ $>0.05$ ) on the number of LB (Figure 2C).

When all the experimental periods were compared, no difference $(P>0.05)$ in LT across periods was observed (Figure 1D). However, LT was numerically lower in the interval of 12 to $6 \mathrm{~h}$ before parturition. This result agrees with previous studies that did not identify any difference in LT duration between the four 6-h periods before calving (Miedema et al., 2011a) and between the last twelve 2 -h periods before calving (Jensen, 2012). The time of day (morning, afternoon, evening, night) had an effect $(P<0.001)$ on the LT with most cows resting more during the night (0000 to $0600 \mathrm{~h}$ ) and less during the afternoon (1200 to $1800 \mathrm{~h}$ ), the morning and evening periods having intermediary results (Figure 2D). 

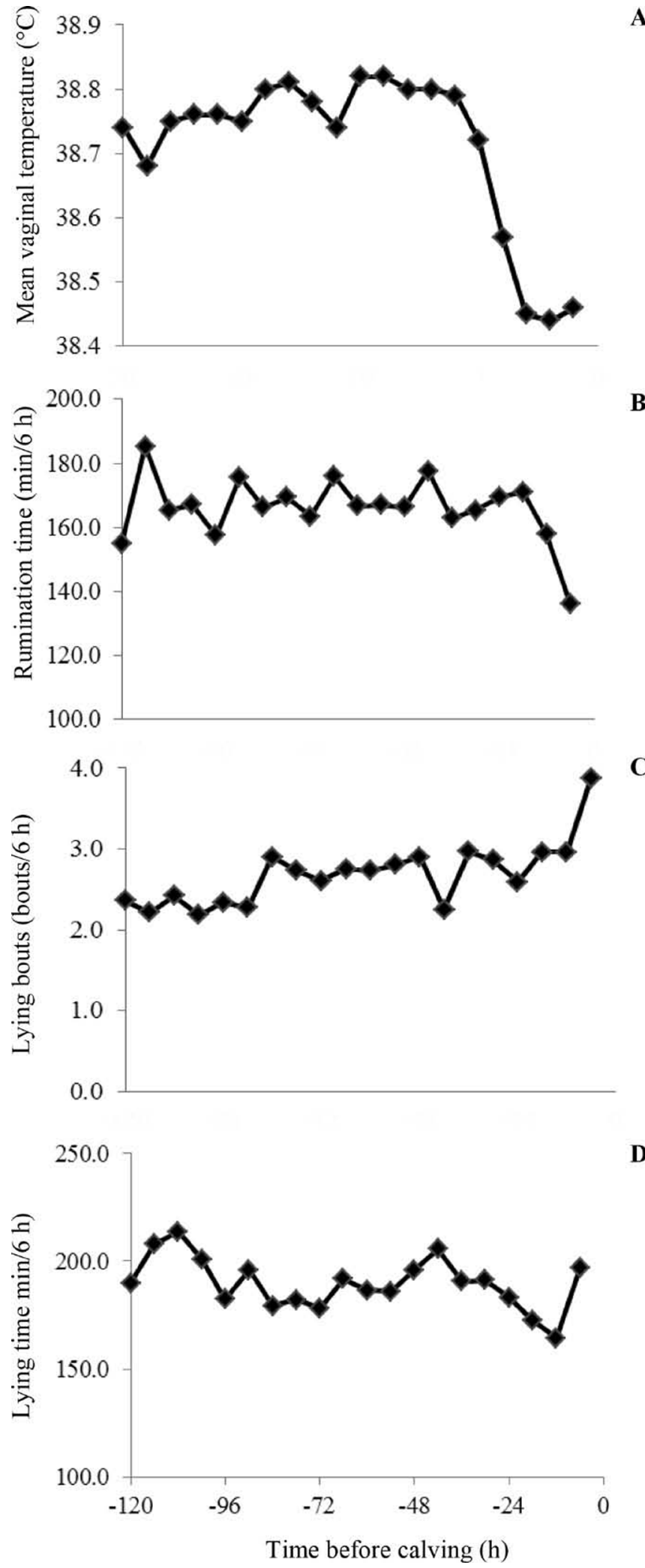

Figure 1. Mean vaginal temperature $(\mathrm{A} ; \mathrm{SEM}=0.08)$, mean rumination time $(\mathrm{B}$; SEM $=13.20)$, mean number of lying bouts $(\mathrm{C}$; SEM $=0.32)$, and mean lying time $(D ; S E M=14.05)$ in the last 120 $\mathrm{h}$ before parturition in multiparous dairy cows $(\mathrm{n}=32)$.

Journal of Dairy Science Vol. 99 No. 2, 2016
A

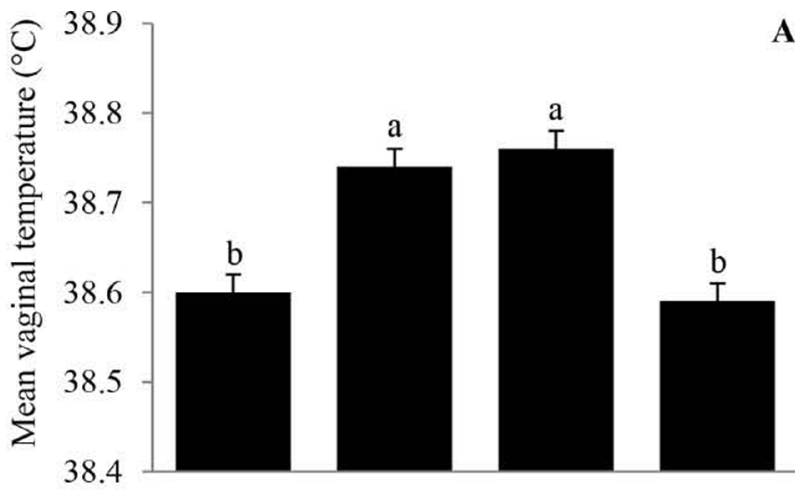

A

B
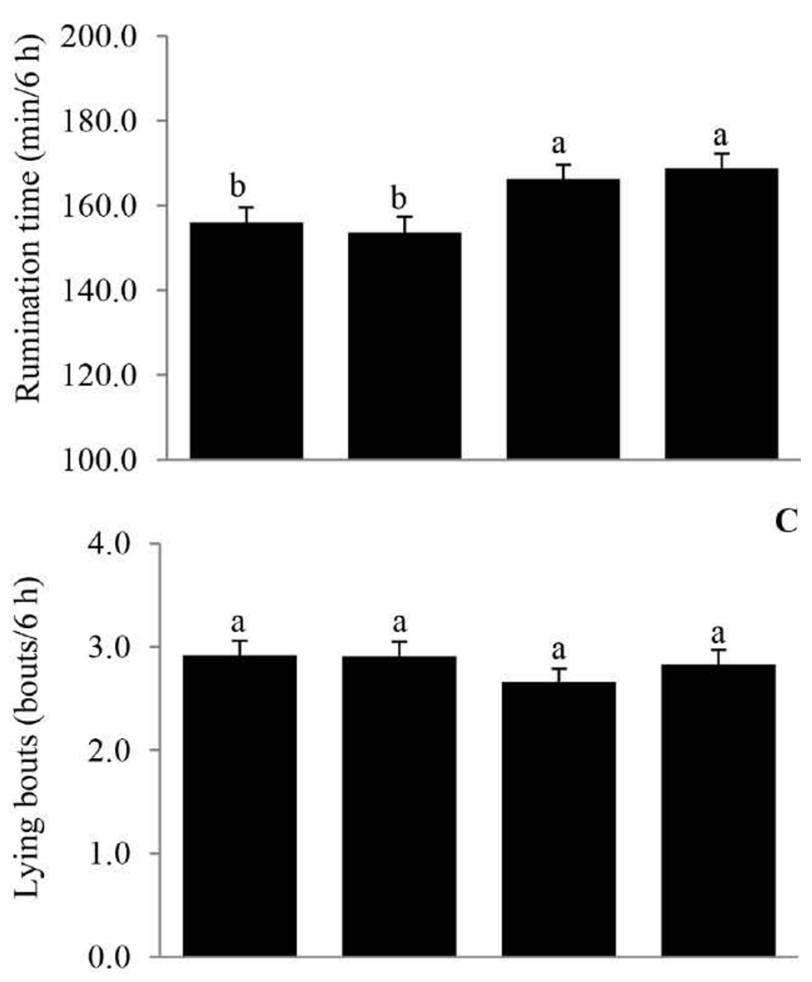

D

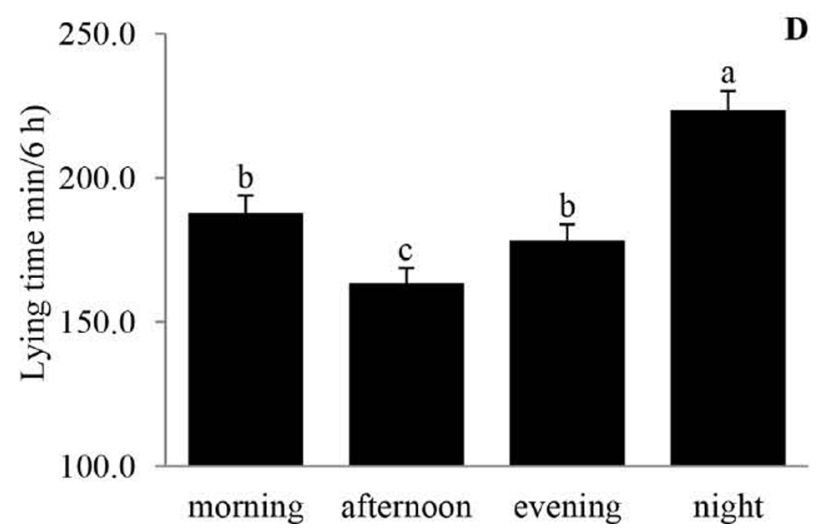

Figure 2. Mean vaginal temperature $(\mathrm{A} ; \mathrm{SEM}=0.02)$, mean rumination time $(\mathrm{B} ; \mathrm{SEM}=3.68)$, mean number of lying bouts $(\mathrm{C}$; $\mathrm{SEM}=0.14)$, and mean lying time (D; SEM = 6.59) during morning, afternoon, evening, and night in the last $120 \mathrm{~h}$ before parturition in multiparous dairy cows $(\mathrm{n}=32)$. 


\section{Test Performance of Calving Indicators}

Changes observed in VT, RT, LB, and LT in relation to the onset of parturition in dairy cows are well documented. However, to our knowledge, the only test characteristics of a decrease of VT measured over $24 \mathrm{~h}$ by a temperature logger as an indicator to predict calving within the next $24 \mathrm{~h}$ is currently available (Burfeind et al., 2011).

Sensitivity, Sp, +PV, and $-\mathrm{PV}$ are necessary factors to evaluate the validity of a predictive test (Burfeind et al., 2011). Among all indicators, a decrease in VT measured by the temperature logger showed the highest predictive value for calving within the next 24, 12, and $6 \mathrm{~h}$ (Table 2). Variation in VT also obtained the greatest area under the curve (AUC). The AUC is a useful tool to assess the diagnostic accuracy of a test and to compare the performance of more than one test for the same outcome (Bewick et al., 2004). The AUC indicates the ability of the test to discriminate cows that will calve and the cows that will not calve within the next 24,12 , or $6 \mathrm{~h}$. Therefore, a test that would be able to differentiate the 2 populations perfectly would have a AUC of 1 , whereas a predictor that is not able to categorize the 2 populations at all would have an AUC of less than 0.5 (Bewick et al., 2004; Burfeind et al., 2011). Several scales are available for AUC interpretation; in general, a test with an AUC $\leq 0.75$ is not clinically useful (Fan et al., 2006).
Vaginal temperature results are comparable with the findings of Burfeind et al. (2011); they measured the test performance to predict calving events within 24 $\mathrm{h}$ of an hourly decrease in VT compared with $24 \mathrm{~h}$ earlier in 3 experiments. In their experiments, the tests obtained a Se ranging from 55 to $76 \%$, a Sp ranging from 71 to $92 \%$, a +PV ranging from 42 to $70 \%$, a $-\mathrm{PV}$ ranging from 86 to $92 \%$, and an AUC ranging from 0.77 to 0.84 with best results achieved when a decrease of $\geq 0.3^{\circ} \mathrm{C}$ was measured. Our data showed optimal test performance to predict calving within the next $24 \mathrm{~h}$ when a decrease of $\geq 0.1^{\circ} \mathrm{C}$ was measured over $24 \mathrm{~h}$. This discrepancy in optimal difference is likely related to the calculation of the cut-off points. In our study, a single cut-off point allowed the optimization of both Se and Sp, which were calculated, whereas Burfeind et al. (2011) calculated several temperature decreases to measure their test characteristics without attempting to optimize both Se and Sp.

The number of LB and RT showed important changes during the last 6 -h period before the onset of calving, whereas LT reached a minimum 12 to $6 \mathrm{~h}$ before calving, and VT were lower during the 18 to $12 \mathrm{~h}$ before calving. Therefore, it appears that the test performance for different prediction times is associated with the period during which the changes in the indicators are most important. Moreover, a decrease in RT and LT and an increase in LB showed lower performances to predict calving with lower Se, Sp, +PV, $-\mathrm{PV}$, and AUC

Table 2. Test performance (95\% confidence interval in parentheses) of optimal cut-off point of decreases in vaginal temperature, rumination time, lying time, and increase in lying bouts measured over 6-h period and compared with the same period $24 \mathrm{~h}$ earlier as a predictor of parturition within 24,12 , and $6 \mathrm{~h}^{1}$

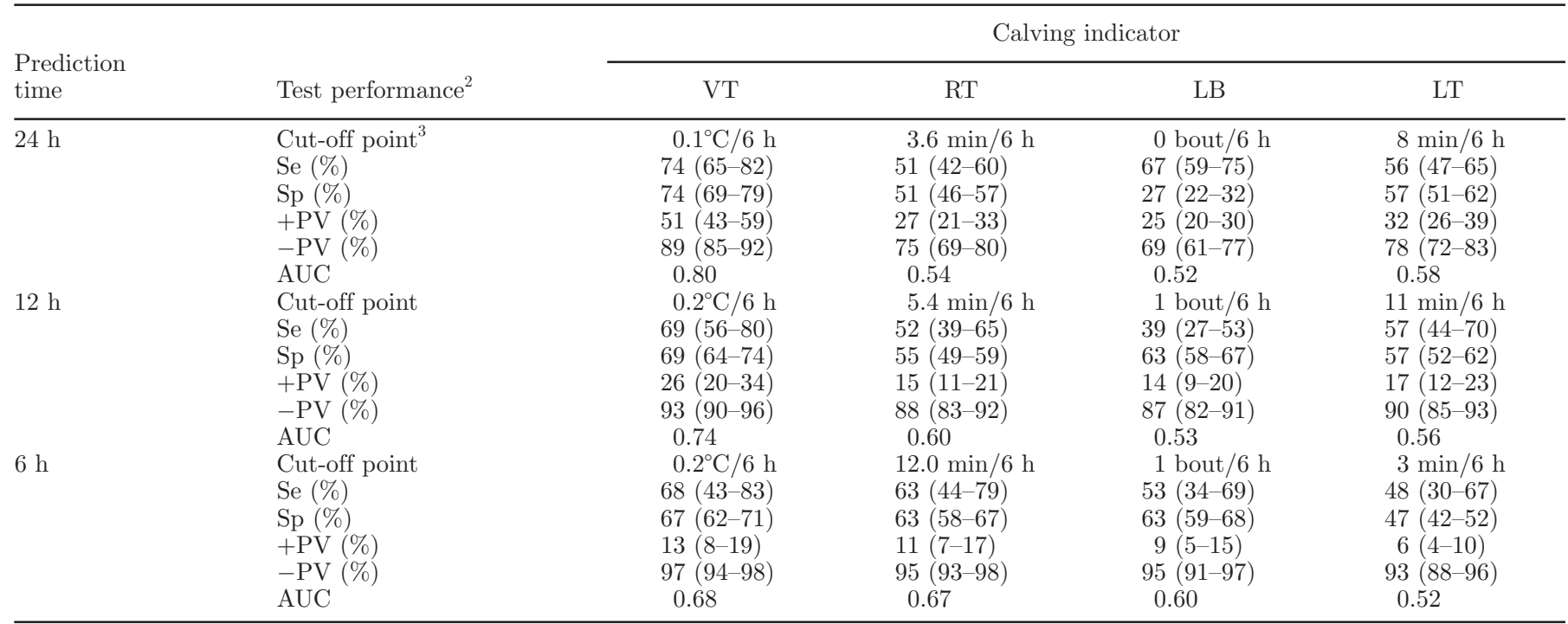

\footnotetext{
${ }^{1}$ Calving indicators: $\mathrm{VT}=$ vaginal temperature; $\mathrm{RT}=$ rumination time; $\mathrm{LB}=$ lying bouts; $\mathrm{LT}=$ lying time.

${ }^{2}$ Test performance: $\mathrm{Se}=$ sensitivity; $\mathrm{Sp}=$ specificity $;+\mathrm{PV}=$ positive predictive value $;-\mathrm{PV}=$ negative predictive value; AUC $=$ area under the curve.

${ }^{3}$ Cut-off point $=$ threshold calculated for each indicator optimizing both Se and Sp for predicting calving.
} 
compared with VT. Those indicators exhibited larger variation between the cows (Table 1) making it harder to calculate a common optimal cut-off point for all the cows. The constant decrease in $\mathrm{VT}$ of $0.3^{\circ} \mathrm{C}$ the day before calving measured in our study and in 2 other studies (Burfeind et al., 2011; Streyl et al., 2011) may indicate less variation between cows for this calving indicator. We speculate that physiological changes might be more stable among cows than behavioral ones, making them more accurate for predicting calving time. Likewise, Matsas et al. (1992) suggest that a reduction in progesterone is the most accurate measure to predict calving within the next $12 \mathrm{~h}$ in dairy cows. This measure is also a physiological indicator which supports our hypothesis.

Each indicator showed low $+\mathrm{PV}$, especially for a prediction of calving within the next $6 \mathrm{~h}$ (Table 2). Sensitivity and Sp are test characteristics that are not affected by the prevalence of positive events (occurrence of calving). However, the predictive values are affected by the Se, the Sp, and by the prevalence of positive events (Bewick et al., 2004). Therefore, when the prevalence of positive events is low, the +PV will be automatically low irrespective of the Se and the Sp, whereas -PV will be high (Bewick et al., 2004). In our study, all calving indicators were summarized in 6 -h periods, and 4, 2, and 1 positive events were defined as the occurrence of calving within the next 24,12 , and 6 $\mathrm{h}$, respectively. This approach explains why lower $+\mathrm{PV}$ and higher $-\mathrm{PV}$ were measured for a prediction of calving within the next $6 \mathrm{~h}$ compared with the prediction of calving within the next 12 and $24 \mathrm{~h}$. Moreover, a test with higher Se and Sp will automatically have higher predictive values. Therefore, the predictive values are a useful tool to evaluate performance of a given test but cannot be used, in our study, to compare the different indicators.

\section{Test Performance of Different Combinations of Calving Indicators}

Test performance of all the possible combinations of the 4 calving indicators were conducted (Table 3 ). Because false positive events were high when predicting individual parameters, the combinations chosen were inclusive (i.e., a prediction of calving was made when all the indicators in its composition were conclusive). Combining the devices to allow simultaneous consideration of the calving indictors enhanced the performance to predict calving within the next 24,12 , or $6 \mathrm{~h}$ compared with when indicators were used independently (Table 3). This result indicates that combining calving indicators can merge the strength of each indicator used in the different combinations. Therefore, the major improvement for the combinations including VT or LT is for a prediction within the next $6 \mathrm{~h}$ when they are combined with RT or LB; the major improvement including $\mathrm{LB}$ or $\mathrm{RT}$ is for a prediction within the next $6 \mathrm{~h}$ when they are combined with VT. The LT had a low effect on the test performance of the combinations of indicators. The low effect of LT in combinations can be related to the lack of specific evolution of this behavior related to the imminence of calving observed in this study when comparing the 6 -h period results. A combination with VT generally improved the results of all the other parameters taken individually.

The combination of VT, RT, LB, and LT obtained the best test performance to predict calving within the next 24 and $12 \mathrm{~h}$, whereas the combination of VT, RT, and LB obtained the best results for predicting calving within the next $6 \mathrm{~h}$ (Table 3). This result emphasizes that the test performance for different prediction times is associated with the period during which the changes are most important. The best results for a combination that does not include VT, which requires vaginal installation, is obtained by combining RT and LB for a prediction in the next $6 \mathrm{~h}$. Such a combination could be advantageous because the devices used to measure RT and $\mathrm{LB}$ require minimal setup and are less invasive for the cows than those required for VT. Despite improved test performance through combining the parameters, $+\mathrm{PV}$ remained low, whereas $-\mathrm{PV}$ were high for all the combinations. A device that would be able to measure a combination of the 4 indicators would not be able to accurately predict the onset of calving but could be a useful tool to assist calving management on dairy farms. More work is needed to determine if the utilization of the tested devices can result in beneficial interventions that justify the cost. Future work should investigate whether other commercially available devices that monitor the tested indicators (i.e., infrared cameras) could improve test performance in predicting the onset of calving. Also, whether devices that monitor other calving indicators (i.e., tail raise) can predict the onset of calving.

Finally, of note, the temperature logger and the accelerometers used in this study are not practical for commercial use because both of them require data downloading. Furthermore, the automated devices used in our study were chosen because they have been validated in previous studies and thus are valuable for research purposes. However, a temperature logger that requires inserting a device into the cow's vaginal cavity may not be popular with producers due to the installation required and the potential for infection and irritation. 


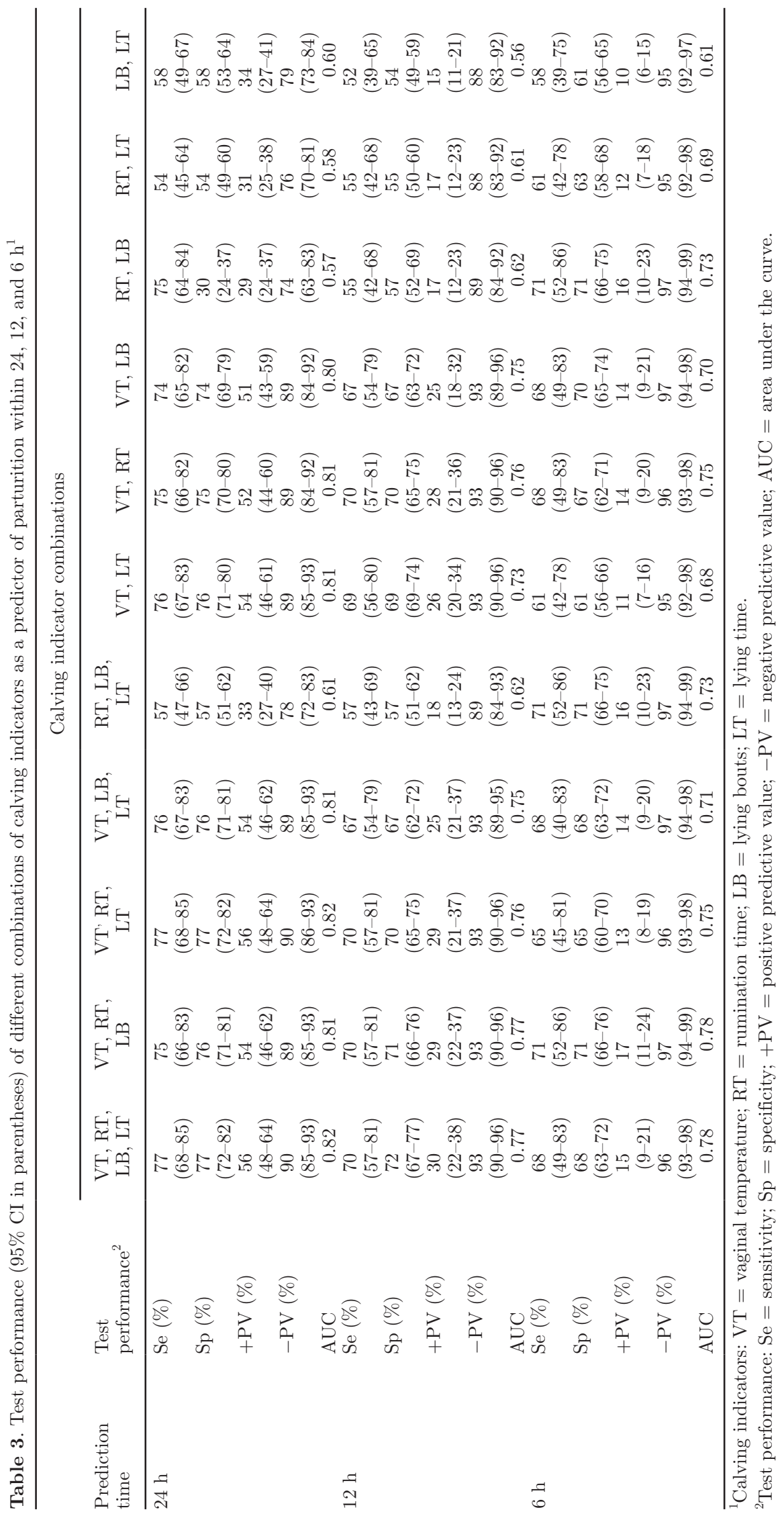




\section{CONCLUSIONS}

Vaginal temperature, RT, LT, and the number of LB showed clear changes associated with the onset of parturition. The technologies used in this study were able to capture those changes. Combining these indicators improved the performance to predict calving within the next 24, 12, and $6 \mathrm{~h}$. Nonetheless, the measured improvement was not sufficient to precisely predict calving. However, these automated devices could be a useful tool to assist calving management on commercial dairy farms.

\section{ACKNOWLEDGMENTS}

This study was funded through les Fonds de recherche du Québec-Nature et technologies (FRQNT) (Québec, QCc, Canada). The first author received a scholarship from the Canadian Dairy Commission in collaboration with Novalait Inc. (Québec, QC, Canada). Appreciation is extended to the farm staff and owner of the commercial dairy farm where this experiment took place for their help and hospitality during the project. The authors also want to extend their appreciation to Linda Saucier for her contribution on this project.

\section{REFERENCES}

Berglund, B., J. Philipsson, and O. Danell. 1987. External signs of preparation of calving and course of parturition in Swedish dairy cattle breeds. Anim. Reprod. Sci. 15:61-79.

Bewick, V., L. Cheek, and J. Ball. 2004. Statistics review 13: Receiver operating characteristic curves. Crit. Care 8:508-512.

Bikker, J. P., H. van Laar, P. Rump, J. Doorenbos, K. van Meurs, G. M. Griffioen, and J. Dijkstra. 2014. Technical note: Evaluation of an ear-attached movement sensor to record cow feeding behavior and activity. J. Dairy Sci. 97:2974-2979.

Büchel, S., and A. Sundrum. 2014. Short communication: Decrease in rumination time as an indicator of the onset of calving. J. Dairy Sci. 97:3120-3127.

Burfeind, O., V. S. Suthar, R. Voigtsberger, S. Bonk, and W. Heuwieser. 2011. Validity of prepartum changes in vaginal and rectal temperature to predict calving in dairy cows. J. Dairy Sci. 94:5053-5061

Dematawewa, C. M. B., and P. J. Berger. 1997. Effect of dystocia on yield, fertility, and cow losses and an economic evaluation of dystocia scores for Holsteins. J. Dairy Sci. 80:754-761.

Fan, J., S. Upadhye, and A. Worster. 2006. Understanding receiver operating characteristic (ROC) curves. CJEM 8:19-20.

Huzzey, J. M., and M. A. G. Von Keyserlingk. 2005. Changes in feeding, drinking and standing behavior of dairy cows during the transition period. J. Dairy Sci. 88:2454-2461.

Jensen, M. B. 2012. Behaviour around the time of calving in dairy cows. Appl. Anim. Behav. Sci. 139:195-202.

Kendall, P. E., C. B. Tucker, D. E. Dalley, D. A. Clark, and J. R. Webster. 2008. Milking frequency affects the circadian body temperature rhythm in dairy cows. Livest. Sci. 117:130-138.
Lombard, J. E., F. B. Garry, S. M. Tomlinson, and L. P. Garber. 2007. Impacts of dystocia on health and survival of dairy calves. J. Dairy Sci. 90:1751-1760.

Matsas, D. J., R. L. Nebel, and K. D. Pelzer. 1992. Evaluation of an on-farm blood progesterone test for predicting the day of parturition in cattle. Theriogenology 37:859-868.

Meyer, C. L., P. J. Berger, K. J. Koehler, J. R. Thompson, and C. G. Sattler. 2001. Phenotypic trends in incidence of stillbirth for Holstein in the United States. J. Dairy Sci. 84:515-523.

Miedema, H. M., M. S. Cockram, C. M. Dwyer, and A. I. Macrae. 2011a. Behavioural predictors of the start of a normal and dystocic calving in dairy cows and heifers. Appl. Anim. Behav. Sci. 132:14-19.

Miedema, H. M., M. S. Cockram, C. M. Dwyer, and A. I. Macrae. 2011b. Changes in the behaviour of dairy cows during the $24 \mathrm{~h}$ before normal calving compared with behaviour during late pregnancy. Appl. Anim. Behav. Sci. 131:8-14.

O'Driscoll, K., L. Boyle, and A. Hanlon. 2008. A brief note on the validation of a system for recording lying behaviour in dairy cows. Appl. Anim. Behav. Sci. 111:195-200.

Oltenacu, P. A., A. Frick, and B. Lindhe. 1988. Use of statistical modeling and decision analysis to estimate financial losses due to dystocia and other disease in Swedish cattle. Pages 353-355 in Proc. 5th Int. Symp. Vet. Epidemiol. Econ., Copenhagen, Denmark.

Pahl, C., E. Hartung, A. Grothmann, K. Mahlkow-Nerge, and A Haeussermann. 2014. Rumination activity of dairy cows in the 24 hours before and after calving. J. Dairy Sci. 97:6935-6941.

Palombi, C., M. Paolucci, G. Stradaioli, M. Corubolo, P. B. Pascolo, and M. Monaci. 2013. Evaluation of remote monitoring of parturition in dairy cattle as a new tool for calving management. BMC Vet. Res. 9:191.

Rajala, P. J., and Y. T. Gröhn. 1998. Effects of dystocia, retained placenta, and metritis on milk yield in dairy cows. J. Dairy Sci. $81: 3172-3181$

Schirmann, K., N. Chapinal, D. M. Weary, L. Vickers, and M. A. G. von Keyserlingk. 2013. Short communication: Rumination and feeding behavior before and after calving in dairy cows. J. Dairy Sci. 96:7088-7092.

Schuenemann, G. M. 2012. Calving Management in Dairy Herds: Timing of Intervention and Stillbirth. The Ohio State University Extension, Columbus.

Schuenemann, G. M., I. Nieto, S. Bas, K. N. Galvao, and J. Workman. 2011. Assessment of calving progress and reference times for obstetric intervention during dystocia in Holstein cows. J. Dairy Sci. 94:5494-5501.

Shah, K. D., T. Nakao, and H. Kubota. 2006. Plasma estrone sulphate (E1S) and estradiol-17- $\beta$ (E2 $\beta$ ) profiles during pregnancy and their relationship with the relaxation of sacrosciatic ligament, and prediction of calving time in Holstein-Friesian cattle. Anim. Reprod. Sci. 95:38-53.

Sheldon, I. M., J. Cronin, L. Goetze, G. Donofrio, and H.-J. Schuberth. 2009. Defining postpartum uterine disease and the mechanisms of infection and immunity in the female reproductive tract in cattle. Biol. Reprod. 81:1025-1032.

Streyl, D., C. Sauter-Louis, A. Braunert, D. Lange, F. Weber, and H. Zerbe. 2011. Establishment of a standard operating procedure fort predicting the time of calving in cattle. J. Vet. Sci. 12:177-185.

Tenhagen, B. A., A. Helmbold, and W. Heuwieser. 2007. Effect of various degrees of dystocia in dairy cattle on calf viability, milk production fertility and culling. J. Vet. Med. A Physiol. Pathol. Clin. Med. 54:98-102.

Vickers, L. A., O. Burfeind, M. A. G. Von Keyserlingk, D. M. Veira, D. M. Weary, and W. Heuwieser. 2010. Technical note: Comparison of rectal and vaginal temperatures in lactating dairy cows. J. Dairy Sci. 93:5246-5251. 